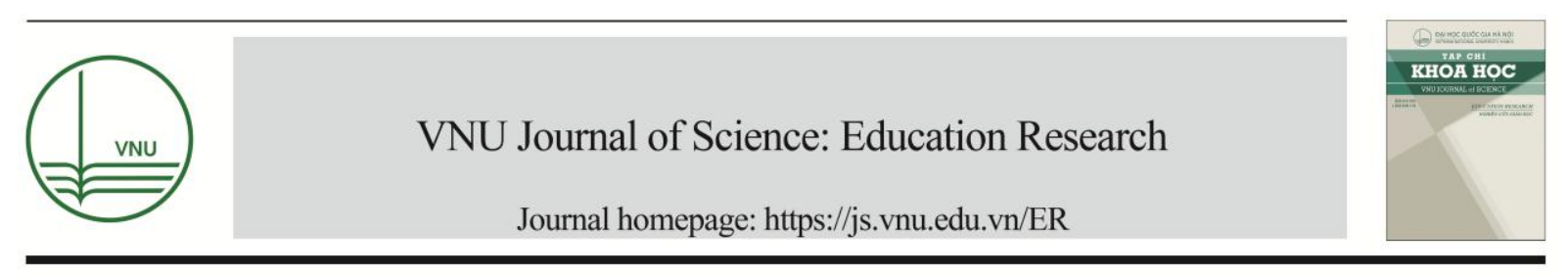

\title{
Definition and Characteristics of "Cyberbullying" among Vietnamese Students
}

\author{
Cong Van Tran ${ }^{1, *}$, Ngoc Hong Phuong Nguyen ${ }^{1}$, Bahr Weiss ${ }^{2}$, \\ Luot Van Nguyen ${ }^{3}$, Dat Ba Nguyen ${ }^{3}$ \\ ${ }^{I}$ VNU University of Education, 144 Xuan Thuy, Cau Giay, Hanoi, Vietnam \\ ${ }^{2}$ Vanderbilt University, Nashville, Tennessee, United States \\ ${ }^{3}$ VNU University of Social Sciences and Humanities
}

Received 25 December 2018

Revised 25 December 2018; Accepted 27 December 2018

\begin{abstract}
The purpose of the present study was to define the term "cyberbullying" from the perspective of middle- and high-school students in Vietnam, detailing its characteristics. The study used qualitative focus groups with Vietnamese students, teachers, parents, school psychologists, and psycho-educational experts in Hanoi, Vietnam. From the perspective of these informants, cyberbullying involves seven characteristics: (a) The indirect transmission of negative, untrue, hateful, and/ or secret, personal information through electronic devices and applications, (b) with the intention to hurt the victim, (c) which may or may not be part of a series of repetitive actions that nonetheless may have ongoing effects, (d) with the perpetrator an individual or a group, (e) in the context of a power imbalance relationship, (f) with the perpetrator(s) able to hide his or her identity, (g) and the bullying able to occur at all times in any place the victim has internet access.
\end{abstract}

Keywords: Definition, characteristics, cyberbullying, students, Vietnam.

\section{Introduction *}

Cyberbullying is becoming a global social and school problem. Multiple studies across the world have reported cyberbullying prevalences among students. Students from 10 to 18 years old have highest risks becoming cyber-victims $[1,2,3,4,5]$. According to a systematic review published by Bottino et al. (2015), the prevalence of cyberbullying in the world ranges from $6.5 \%$ to $35.4 \%$ [6]. The prevalence of

\footnotetext{
* Corresponding author. Tel.: 84-978205905.

Email: congtv@vnu.edu.vn

https://doi.org/10.25073/2588-1159/vnuer.4212
}

cyberbullying in Vietnam has been reported in several studies in recent years. The results of a study on 736 middle- and high-school students in Hanoi, Ha Nam, and Hai Duong showed that $24 \%$ of participants were victims of at least one form of cyberbullying [7]. Another study conducted on 493 students in 3 high schools in Hanoi, Ha Nam, and Hai Duong showed that $35.7 \%$ were victims of cyberbullying [8]. A study of over 500 high-school students in Da Nang by Nguyen, H.T.B. et al. (2017) found that $19.3 \%$ of the students were perpetrators and $16.7 \%$ of the students were victims of cyberbullying [9]. However, studies in Vietnam on this topic have same limitation, of using 
definitions acquired through synthesis from international studies, and the local appropriateness of the definitions are not clear. International authors have shown varying perspectives on the different ways of identifying cyberbullying among subjects from countries with different cultures $[10,11]$.

Development of conceptual definitions is a challenge for all research fields, especially in the context where researchers are exploring a new scientific problem, such as cyberbullying. A number of studies around the world have been conducted to develop and clarify the definition of cyberbullying as well as to explore the characteristics of cyberbullying. Cyberbullying has been defined by many researchers in different ways, in varying degrees of depth. So date, according to a report by the European Parliament, there is no single definition of cyberbullying and bullying that has been agreed upon at the international or European level. Efforts to increase understanding cyberbullying, however, continue through international organizations within the EU [12].

"Cyber" refers something related to computers or the Internet. In the Oxford dictionary, "cyber" refers characteristic of computer culture, information technology, and virtual reality. According to the Cambridge dictionary, "cyber" is a precursor to the inclusion, involvement or use of computers, especially the internet. Olweus (2013) argues that cyberbullying is similar to face-to-face bullying (traditional bullying) but occurs through electronic devices [13]. In many cases, cyberbullying is defined based on Olweus' original bullying definition [14, 15], whereby the authors take three main points to make (1) intentionally harm, (2) repetition, and (3) in interpersonal relationship with power imbalance [16].

However, some researchers have expressed concern of that borrowing definitions of traditional bullying to define cyberbullying may not lead to adequate descriptions of cyberbullying [17, 18, 19]. Cyberbullying is different from traditional bullying in some aspects [20, 21, 22]. First, the scope of cyberbullying is larger than traditional bullying, with just one click students can spread rumors to thousands of people on the internet. Second, it is difficult or impossible for the cyber-victim to fully escape the threat situation. With traditional bullying, victims have certain times at school but at other times may at home or other potentially safe places; while cyberbullying can continue throughout the day and night, regardless of where the individual is. Third, unlike traditional bullying, cyberbullying is not a face-to-face experience, and the perpetrator can be anonymous. Fourth, electronic content can be difficult to remove and functionally permanent, so victims may experience one incident bullying repeatedly (e.g., when a rumor is posted in a chat room) [23]. Thus, a number of researchers have concluded that independent definitions that use part or all of Olweus' traditional bullying definition should be extended [19]. Tokunaga (2010), for example, has proposed that cyberbullying is any act done through electronic or digital means by individuals or groups that repeatedly send aggressive messages to hurt or annoy others [19].

One of the first researchers to introduce an independent definition for "cyberbullying", was Bill Belsey (2005), a Canadian educator. He defined cyberbullying as using information and communication technology such as email, mobile phone or text message, or a personal website to harm someone's honor intentionally, repeatedly, via hostile behavior by an individual or group [24]. In later studies, the definition of cyberbullying has been more specific about the ways and means used for bullying. For instance, cyberbullying has been defined as: (a) verbal bullying or relationship bullying conducted via electronic media or wireless technology equipment [17]; (b) aggression that occurs through modern technological devices, especially mobile phones and the internet [25, 26]; (c) is the transmission or posting of harmful or malicious messages or images using 
the internet or other digital devices of communication [27]; (d) is the repeated aggressive behavior of an individual or group to an individual through communication technology such as e-mail, mobile phone, text messages, instant messages, personal websites or blogs [28]. In sum, cyberbullying is a form of aggression that is done through electronic devices [29]. Thus, cyberbullying has characteristics of traditional bullying but also distinctive characteristics [30].

However, one complexity in the definition of cyberbullying is that repetition of behavior is a central characteristic of bully, but cyberbullying takes place in contexts where "repetition" may be hard to differentiate or define. As mentioned above, a single cyberbullying behavior such as posting a rumor in a chat room can produce ongoing effects. The victim may experience being bullied repeatedly as new friends or acquaintances read the posting, although the bully may no longer be engaged [31, 32, 33, 34]. Therefore, even only a one-time act affect people over and over again.

In Vietnam, at present the definition of cyberbullying is largely based on the synthesizing of definitions from studies in different countries [7, 9]; no definition has been derived from the Vietnamese perspective, in the context of Vietnamese culture. There the goal of the present study was to formally definition and discuss characteristics of cyberbullying in Vietnam, according to the culture and views of Vietnamese people. The definition and characteristic discovered in this study are hoped to be the starting point for further research into this issue, and applied in practice by school psychologists and relevant agencies and organizations to identify cyberbullying problems in students.

\section{Methodology}

The present study conducted focus groups with the following participants: one group of 5 students from 5 different middle and high schools (10 - 18 years), one group of 5 parents with children in middle or high school, one group of 5 teachers at middle, and high schools and community college, one group of 5 psychologists working with children and adolescents, and one group of 6 experts in the field of psychology and education at research institutes and universities. The focus group discussions were centered on: (1) what is cyberbullying, (2) what are cyberbullying behaviors, and (3) characteristics of cyberbullying behaviors. Each group discussion was conducted in two and a half hours.

\section{Results}

Most participants defined cyberbullying by giving examples, and then delineating the characteristics of the examples. Summarizing across the participants, cyberbullying was seen as having the following characteristics:

1. Indirectly transmitting negative, untrue, hateful, secret, and / or personal information through electronic devices and applications. All participants indicated that cyberbullying is conducted through the internet, using technological devices that can access the internet. Cyberbullying was seen as occurring most commonly on social network applications (e.g., Facebook), but also during online games, group chat messages, email, etc. For psychologists working in schools and hospitals, cyberbullying can take place not just on the internet but also through the mobile phone network via text messaging. According to the student group: "Someone can exploit all data from personal favorites, where the family is, where people are from, photos, videos, all their personal information to bully others, according to many people online, many hurtful comments". See Table 1.

2. Intention to hurt the victim(s). All groups agreed that a central characteristic of bullying is the intentional and purposeful intent to harm. The intent to harm is one of the if not 
the central characteristic of the definition of cyberbullying. For instant, according to the teacher group, cyberbullying "must cause some loss for the victim", and according to the psychologist group, cyberbullying occurs when "When someone transmits something that makes the other person feel uncomfortable, affects his or her dignity, or their mental or physical health". According to the professionals, cyberbullying is an intentional harmful behavior, but different from harassment. "If an internet user posts something that does not have a specific target (e.g., "I hate you"), it still can be cyberbullying. Individuals who read these posts may feel specifically targeted, and experience being bullied."

3. Repetition. Most of the focus group discussions included discussion that frequency or repetition is not an important factor in determining whether a behavior is a cyberbullying. According to the expert group, "frequency is not the problem, but the degree of harm, when everything is exposed." According to the teachers, "Just a single action can be called bullying, if it is strong enough." The psychologists also indicated that repetition was not central to the definition, "For example, it is possible to attack an individual aggressively enough only once, but it will still have a longterm effect on the person being bullied". Thus, a single behavior can have a sustained impact in cyberspace, as information is spread and transmitted continuously. This may be due to the nature of the mechanism through which information is spread, not necessarily due to the bully carrying out repeated behaviors.

4. Power imbalance. Cyberbullying involves behaviors where a person or group of persons is stronger than the intended victim in the opinion of the majority of the audience. This was the consensus of all the groups. A group of students stated that "Usually when are being bullied you will feel isolated, no one is on your side on the network, and you are weak. According to the expert group, cyberbullying involves "the intimidation of one person/group by another person/group that is more powerful than the other group, so the behavior is morally intimidating.

5. Perpetrators can attack anonymously or fake their identity. According to the group of experts, in traditional bullying the identity of the bully generally is clear and public, where a specific individual and group can be identified. However, in cyberbullying, the perpetrator "can be anyone". According to the psychologists and teachers, cyberbully can be anonymous or the bully can pretend to be someone else to cause harm to this third person. According to the teachers, in some cases the bullies and victims are not even acquainted with each other "they hurt an unfamiliar person ... they talk in public chat group, then fight each other without know the other person".

6. Cyberbullying can affect victims at any time of the day or night. All of the groups indicated that cyberbullying can occur at anytime and anyplace. According to the expert group, "cyberbullying affects people everywhere, all the time," and that part of the problem with cyberbullying is that the victim "is always affected, and there is always a witness on the internet. According to the group of teachers, the fact that cyberbullying can occur at any time reflects that tact that "internet is information that you cannot control". Moreover, the internet is a second life that is always associated with students, with the teachers noting "students share their life on social networks, that is it is their second life, then ... they can receive so much hatred". Because of this characteristic that cyberbullying can affect anyone at any time, the impact of cyberbullying on victims is difficult to control and particularly harmful.

7. The perpetrator can be an individual or group. All of the participant groups agreed that cyberbullying can be from an individual, or an online group, For instance, the student group said "bullying groups can be large or small or a single person, they support their own side". According to the psychologists and school counselors, bullying can "involve an individual or group, where they say bad things about 
someone who studies hard all day, teasing them as a bookworm".

The participant groups also noted that cyberbullying can cause face-to-face bullying, and that victims can be both cyberbullied and rationally bullied. This was reflected in the specific behavioral instances that groups provided. According to the group of teachers, for instance, "So today a student is upset with someone online, and he or she brings it their social network at school, that can be the beginning of the direct bullying of each other." The teachers also suggest that "two students look at each other in school, one girl thinks the other looks at her mean, so she will post a long note about the other one, and tag that girl." According to the teacher group, "You sense the weakness of your friend, intimidate the friend and bully them to do as you like, if he/she does not do it, you will post these things on the internet." According to the group of psychologist, school counselor: "middle and high school students will come together and have a fight, then go online to post a video of the fight on the internet.

Table 1. Cyberbullying behaviors reported by psycho-educational experts, psychologists, teachers, parents, and students

\begin{tabular}{|c|c|}
\hline Group & Cyberbullying behavior \\
\hline $\begin{array}{l}\text { Psycho- } \\
\text { educational } \\
\text { experts }\end{array}$ & $\begin{array}{l}\text { "Spread information on social networks" } \\
\text { "Take pictures to post with bad intentions" } \\
\text { "Send a message via phone, Facebook with bad intentions" } \\
\text { "Bad video upload to YouTube" } \\
\text { "Creating the untrue information" } \\
\text { "Edit photo" } \\
\text { "Create a fake account (still transfer a fake news)" } \\
\text { "Block / excluded from the group - isolation (I'm blocked from being meaningful, } \\
\text { important group to me - I belong to that group)" } \\
\text { "Sharing other people's information without their permission" }\end{array}$ \\
\hline $\begin{array}{l}\text { Psychologists, } \\
\text { counselors }\end{array}$ & $\begin{array}{l}\text { "Threat of shopping for weapons in online games" } \\
\text { "Read each other's comments are starting to feel uncomfortable then start to threaten } \\
\text { each other" } \\
\text { "Group fighting then post on social network" } \\
\text { "... conflicts in classrooms then meet and fight outside and then post on social network" } \\
\text { "When hated, post something on Facebook to imply hints to hurt others" } \\
\text { "Set up a social network group, then say bad things about other peers who study hard all } \\
\text { day, like a bookworm" } \\
\text { "In a classroom there will be a student who hated most, and the class students will create } \\
\text { a group saying bad things about that student" } \\
\text { "A girl who likes a boy may show her affections on Facebook, then other students may } \\
\text { blame her for expressing affection to the boy" } \\
\text { "Another case when a student is better at playing games than others, he will scold or } \\
\text { threaten other students" } \\
\text { "Directly mention about the victim or through another object or other form to repudiate } \\
\text { the victim's dignity" } \\
\text { "Send pornographic photos" } \\
\text { "Socially it may be related to an exclusion group" } \\
\text { "Calling all people, for instance the groups, such as grouping so many people, get the } \\
\text { majority opinion to hurt the victims psychologically" } \\
\text { "Bad smelling about each other, one bad smelling one another, bad smiles, offensive } \\
\text { words" } \\
\text { "Saying bad and inappropriate words, or speaks libelously, or speaks of irony or }\end{array}$ \\
\hline
\end{tabular}




\begin{tabular}{|c|c|}
\hline & $\begin{array}{l}\text { disparagement, or what is called provocation, libel, overstatement, wrong message" } \\
\text { "Take pictures, get pictures to the network to ridicule" } \\
\text { "Write a very long talk about the bad points of people to ridicule, denigrate" }\end{array}$ \\
\hline Teachers & $\begin{array}{l}\text { "Post status with warning, put face down, threatening content" } \\
\text { "Students don't know each other, but they can talk friendly then suddenly run into } \\
\text { conflict..." } \\
\text { "Openly call others to participate in offline fights" } \\
\text { "Words written on the internet have tendency of intimidating, imposing others to share" } \\
\text { "Allude on social networks" } \\
\text { "Comment directly or post something then tag to threaten the victim" } \\
\text { "Post status or threatening image and tag the victim" } \\
\text { "Sometimes it's just a picture, not a scary or sensitive picture, but the picture itself } \\
\text { publicize a secret" } \\
\text { "A student grasp the weakness of another friend, intimidate the other friend, bully the } \\
\text { other friend to do what s/he wants otherwise s/he will post the weakness so everyone will } \\
\text { know" } \\
\text { "Post status or photo, bully by grasping the weakness and intimidation others" } \\
\text { "Low security, Facebook accounts are hacked and information are disclosed, affect the } \\
\text { dignity... the information is used to bully others" } \\
\text { "Hack Facebook... use the hacked Facebook account to post disparaging words to others" } \\
\text { "For example, a student log his/her Facebook account in a computer of internet cafe/shop } \\
\text { and forget to log out, someone may use that opening account to post terrible things, that } \\
\text { can be considered cyberbullying" }\end{array}$ \\
\hline Parents & $\begin{array}{l}\text { "Disclose personal information" } \\
\text { "Blaming one another, intimidating, defaming and posting publicly" } \\
\text { "Allude, hint" } \\
\text { "Challenge each other, post the threats" } \\
\text { "Stick pictures like knives to threaten directly" } \\
\text { "Put up a video clip and include a challenging paragraph... " } \\
\text { "Repeated instant messaging, threatening messages, text messages to each other over the } \\
\text { phone, Zalo, Messengers to threat others" } \\
\text { "For example, just a message: tomorrow morning I will wait for you at the school gate, } \\
\text { do you dare to go to school? The victim can be very scared " }\end{array}$ \\
\hline Students & $\begin{array}{l}\text { "Bullying on the Internet I witnessed is when other students pulled out a student's } \\
\text { personal information to tease" } \\
\text { "They will look for and use the old information to smear and ruin the dignity of people" } \\
\text { "People pealed out someone's private life, romantic stories, and other aspects to } \\
\text { humiliate others, to them feel miserable, when the perpetrators feel it fun" } \\
\text { "People often use bad words and comments to humiliate the victims, or people bully on } \\
\text { the Internet, people will use personal information, people spread bad things, it is not } \\
\text { good for people who are bullied and people give as many people as possible" } \\
\text { "This evil comments, stigmatized images..." } \\
\text { "The bullies will often take the information that victims post on the internet, such as the } \\
\text { Facebook name, Chinese name... Or the pictures that a student posted, s/he may be happy } \\
\text { and feel fun with that, but the bullies can use them as a tool to attack, process the photo } \\
\text { to bully..." } \\
\text { "Attack, threaten, ruin others' faces, humiliate, make the victim cannot raise their heads" }\end{array}$ \\
\hline
\end{tabular}

\section{Discussion and conclusions}

The focus group discussions provide for a definition of cyberbullying based on the perspective of education experts, psychologists, and parents and students in Vietnam. Their definition is that cyberbullying occurs when a person or group of people intentionally post, 
send or share negative, untrue, threatening, hostile, or personal information of others with the intent to harm the victim often by damaging the victim's reputation, using internet applications and electronic devices such as computers and smartphones. Cyberbully can be anonymous or with a false identity, with cyberbully potentilly unacquainted in the real world with the person being bullied. Cyberbullying can occur anywhere, at any time. The study also found that traditional face-toface bullying and cyberbullying can occur with the same students, and each form of bullying potentially is a cause of the other.

In many ways, cyberbullying as defined by these Vietnamese participants is similar with traditional bullying. As with traditional bullying, cyberbullying involves (a) attempting to cause harm to another (b) that is intentional (c) within the context of a power imbalance [16]. One area where cyberbullying appears at least somewhat different is in regards to repetition. Our participants indicated that the behavior itself may not be repetitive but still cyberbullying if the aggressive act is sufficiently strong. In addition, because of the nature of the internet, a single aggressive act can continue to have ongoing impact because information on the internet continues to be available indefinitely. In addition, information can be reposted by others than the initial prepatrator, in many places, for different reasons. Once messages etc. are posted, they can spread beyond the control of the victim or the perpetrator [31, 32, 33, 34]. In addition, in cyberbullying the perpetrator(s) potentially may hide their identity, and the bullying is able to occur at all times and places, such as when a student is at home in the evening with his or her family, if on the internet. These characteristics also differ from traditional bullying.

These findings have implications for individuals in Vietnam working to help or reduce the effects of cyberbullying on victims. First, as noted above, victims of cyberbullying may need to be prepared to cope with ongoing dissemination of negative information, even if the relationship with the perpetrator is resolved. The fact that the bully may hide his or her identity perhaps can be taken as an indicator that the bully themselves is afraid, which potentially can reduce the impact of the bullying. The fact that bullying can occur whenever the student is online is another reason for students to reduce unnecessary time spent online.

Ultimately, however, support for victims of cyberbullying will for the most part be similar to support for traditional bullying $[35,36]$. To achieve effective results, first we need schoolwide cyberbullying intervention and prevention programs, as interventions focused on the whole school have been found to be more effective in reducing cyberbullying than interventions via classroom curricula or social skills training alone [37]. The program should involve all stakeholders including school administrators, teachers, school staff, students, and their families to develop culturallycompatible student support strategies, school rules and policies regarding school technology use and cyberbullying. Stakeholders should also work together to develop general behavioral management strategies that may reduce cyberbulling through diffusion effects, and foster links between families, schools and communities. Delivering awareness on bullying to all stake holders is very important, as a unified approach will be more effective. Goals of the program should be to (a) raise the school's awareness of cyberbullying, helping schools and families to be aware of the signs and consequences of cyberbullying; (b) provide appropriate support for cyberbullying victims; and (c) equip students with coping strategies when they are cyberbullied.

Second, the program should encourage students to help their peers when they are cyberbullied. Research results showed that students witness many cases of cyberbullying on their peers. The role of the witnesses is very important, and they are in fact the key to reducing cyberbullying. Research has found that the largest group in the school environment 
in relation to cyberbullying is the witness, who can change the school climate of cyberbullying by making it unacceptable [38]. The witnesses may choose to "stand up" against the bullies and support the victims, encourage intervention from peers or adults, or join in bullying, or passively observe without providing any support [39]. The mission of the cyberbullying prevention and intervention program is to motivate students to stand up against bully and support the victims, raising awareness about the role of witnesses, and provide students with strategies and resources that you can seek help when witnessing bullying. Finally, research has found that online risk behaviors such as posting sensitive images, sharing personal information increase the likelihood cyberbullying [40, 41]. Hence intervention and prevention program should also focus on educating online safety behaviors for students.

\section{Acknowledgments}

This research was funded by the National Foundation for Science and Technology Development (NAFOSTED) through research project number 501.99-2015.02.

\section{References}

[1] Smith, P., Mahdavi, J., Carvalho, M., Tippett, N. (2006), An investigation into cyberbullying, its forms, awareness and impact, and the relationship between age and gender in cyberbullying, A Report to the Anti-Bullying Alliance, Goldsmiths College, University of London.

[2] Beran, T., Li, Q. (2007), The Relationship between Cyberbullying and School Bullying, Journal of Student Wellbeing, 1, 2, 15-33.

[3] Huang, Y., Chou, C. (2010), An analysis of multiple factors of cyberbullying among junior high school students in Taiwan, Computers in Human Behavior, 26, 1581-1590. From: http://www.elsevier.com/locate/comphumbeh.

[4] Wade, A., Beran, T. (2011), Cyberbullying: The new era of bullying, Canadian Journal of School Psychology, 26, 1, 44 - 61.
[5] Mishna, F., Khoury-Kassabri, M., Gadalla, T., Daciuk, J. (2012), Risk factors for involvement in cyber bullying: Victims, bullies and bullyvictims, Children and Youth Services Review, 34, 63-70.

From: www.elsevier.com/locate/childyouth.

[6] Bottino, S. M. B., Bottino, C., Regina, C. G., Correia, A. V. L., \& Ribeiro, W. S. (2015). Cyberbullying and adolescent mental health: systematic review. Cadernos de saude publica, 31, 463-475.

[7] Tran, C. V.; Nguyen, N. P. H.; Ngo D. T.; Nguyen T. T. (2015), Students' coping strategies with cyber-victimization. VNU Journal of Sciences: Educational Research, Vol. 31, No. 3, 11-24.

[8] Nguyen, N. P. H.; Tran, C.V. (2016), Consequences of cyberbullying among high school students, International conference proceedings: "Psychological trauma and support activities", Vietnam National University Publishing House, 51-63.

[9] Nguyen, H. T. B; Tran C.V, (2017), Cyberbullying among high school students in Da Nang, Proceedings of the 3rd International Conference on Southeast Asian Psychology: "Human Happiness and Sustainable Development", RCP 2017, (2), 355-363.

[10] Menesini, E., Nocentini, A., Palladino, B. E., Frisén, A., Berne, S., Ortega-Ruiz, R.,... \& Naruskov, K. (2012). Cyberbullying definition among adolescents: A comparison across six European countries. Cyberpsychology, Behavior, and Social Networking, 15(9), 455-463.

[11] Naruskov, K., Luik, P., Nocentini, A., \& Menesini, E. (2012). Estonian students' perception and definition of cyberbullying. Trames: A Journal of the Humanities \& Social Sciences, 16(4).

[12] European Parliament's Committee (2016), Cyberbullying among young people, http://www.europarl.europa.eu/RegData/etudes/S TUD/2016/571367/IPOL_STU(2016)571367_EN. pdf

[13] Olweus, D. (2013). School bullying: Development and some important challenges. Annual review of clinical psychology, 9, 751-780.

[14] Hinduja, S., \& Patchin, J. W. (2010). Bullying, cyberbullying, and suicide. Archives of suicide research, 14(3), 206-221.

[15] Smith, P. K., Mahdavi, J., Carvalho, M., Fisher, S., Russell, S., \& Tippett, N. (2008). Cyberbullying: Its nature and impact in secondary 
school pupils. Journal of child psychology and psychiatry, 49(4), 376-385.

[16] Olweus, D. (2010). Understanding and researching bullying: some critical issues (pp. 9-33). In. S. Jimerson; S. Swearer \& D. Espelage (Eds.). Handbook of bullying in schools: an international perspective.

[17] Bauman, S. (2007), Cyberbullying: a Virtual Menace, Paper to be presented at the National Coalition Against Bullying National Conference, Melbourne, Australia.

[18] Slonje, R., Smith, P. K., \& FriséN, A. (2013). The nature of cyberbullying, and strategies for prevention. Computers in human behavior, 29(1), 26-32.

[19] Tokunaga, R. S. (2010). Following you home from school: A critical review and synthesis of research on cyberbullying victimization. Computers in human behavior, 26(3), 277-287.

[20] Álvarez García, D., Núñez Pérez, J. C., Álvarez Pérez, L., Dobarro González, A., Rodríguez Pérez, C., \& González Castro, M. P. (2011). Violencia a través de las tecnologías de la información y la comunicación en estudiantes de secundaria. Anales de psicología.

[21] Garaigordobil, M. (2011). Prevalencia y consecuencias del cyberbullying: una revisión. International Journal of Psychology and Psychological Therapy, 11(2).

[22] Stewart, R. W., Drescher, C. F., Maack, D. J., Ebesutani, C., \& Young, J. (2014). The development and psychometric investigation of the Cyberbullying Scale. Journal of interpersonal violence, 29(12), 2218-2238.

[23] Buelga, S., Cava, M. J., \& Musitu, G. (2010). Cyberbullying: victimización entre adolescentes a través del teléfono móvil y de Internet. Psicothema, 22(4), 784-789.

[24] Belsey, B. (2005), Cyberbullying. From: www.cyberbullying.ca.

[25] Slonje, R., \& Smith, P. K. (2008). Cyberbullying: Another main type of bullying?. Scandinavian journal of psychology, 49(2), 147-154.

[26] Li, Q. (2008). A cross-cultural comparison of adolescents' experience related to cyberbullying. Educational Research, 50(3), 223-234.

[27] Willard, N, E. (2007), The authority and responsibility of school officials in responding to cyberbullying, Journal of Adolescent Health, 41, S64-S65.
[28] Aricak, T., Siyahhan, S., Uzunhasanoglu, A., Saribeyoglu, S., Ciplak, S., Yilmaz, N., \& Memmedov, C. (2008). Cyberbullying among Turkish adolescents. Cyberpsychology \& behavior, 11(3), 253-261.

[29] Smith, P. K. (2012). Cyberbullying and cyber aggression. In Handbook of school violence and school safety (pp. 111-121). Routledge.

[30] Gámez-Guadix, M., Orue, I., Smith, P. K., \& Calvete, E. (2013). Longitudinal and reciprocal relations of cyberbullying with depression, substance use, and problematic internet use among adolescents. Journal of Adolescent Health, 53(4), 446-452.

[31] Rogers, V. (2010), Cyberbullying: Activities to Help Children and Teens to Stay Safe in a texting, twittering, social networking world, Jessica Kingsley Publishers.

[32] Connell, N. M., Schell-Busey, N. M., Pearce, A. N., \& Negro, P. (2014). Badgrlz? Exploring sex differences in cyberbullying behaviors. Youth Violence and Juvenile Justice, 12(3), 209-228.

[33] Patchin J., Hinduja, S. (2014), Words Wound: Delete Cyberbullying and Make Kindness Go Viral, Free Spirit Publishing.

[34] Peterson, J.M. (2013), How to Beat Cyberbullying, First Edition, The Rosen Publishing Group, Inc.

[35] Raskauskas, J., \& Huynh, A. (2015). The process of coping with cyberbullying: A systematic review. Aggression and violent behavior, 23, 118125.

[36] Völlink, T., Bolman, C. A. W., Dehue, F., \& Jacobs, N. C. L. (2013). Coping with cyberbullying: Differences between victims, bully-victims and children not involved in bullying. Journal of Community \& Applied Social Psychology, 23(1), 7-24. doi: 10.1002/casp.2142

[37] Cantone, E., Piras, A. P., Vellante, M., Preti, A., Daníelsdóttir, S., D’Aloja, E.,... \& Bhugra, D. (2015). Interventions on bullying and cyberbullying in schools: A systematic review. Clinical practice and epidemiology in mental health: $C P \& E M H, 11$ (Suppl $1 \mathrm{M} 4), 58$.

[38] Padgett, S., \& Notar, C. E. (2013). Bystanders Are the Key to Stopping Bullying. Universal Journal of Educational Research, 1(2), 33-41.

[39] Thornberg, R., Tenenbaum, L., Varjas, K., Meyers, J., Jungert, T., \& Vanegas, G. (2012). Bystander motivation in bullying incidents: To intervene or not to intervene?. Western Journal of Emergency Medicine, 13(3), 247. 
[40] Gámez-Guadix, M., Borrajo, E., \& Almendros, C. (2016). Risky online behaviors among adolescents: Longitudinal relations among problematic Internet use, cyberbullying perpetration, and meeting strangers online. Journal of Behavioral Addictions, 5(1), 100-107.
[41] Vismara, M. F. M., Toaff, J., Pulvirenti, G., Settanni, C., Colao, E., Lavano, S. M., ... \& Montera, R. (2017). Internet use and access, behavior, cyberbullying, and grooming: results of an investigative whole city survey of adolescents. Interactive journal of medical research, 6(2). 